\title{
Changing Spectrum of Infections in Childhood Nephrotic Syndrome
}

\author{
ljas Hassan ${ }^{1} \cdot$ Jutang Babat Ain Tiewsoh ${ }^{2} \cdot$ Pallab Ray $^{2} \cdot$ Lesa Dawman ${ }^{1} \cdot$ Vinay Rathore $^{1} \cdot$ Deepti Suri $^{1}$. \\ Karalanglin Tiewsoh ${ }^{1}$ (B)
}

Received: 11 January 2019 / Accepted: 31 May 2019 /Published online: 17 June 2019

(C) Dr. K C Chaudhuri Foundation 2019

To the Editor: Nephrotic syndrome (NS) is a common childhood glomerular disease. Infections are an important cause of morbidity and mortality, with bacterial infection of upto $21.2 \%$ [1]. Studies show different infections occur at different time periods [2,3]. Knowledge of existing infection spectrum and common organisms in a particular region is important for deciding antibiotic policies.

We performed a cross-sectional study enrolling all children with NS (as defined by KDIGO [4]) admitted with infection in Pediatric Nephrology ward, Advanced Pediatrics Centre, PGIMER, Chandigarh, India from January 2017 through June 2018. The study was approved by the Institute Ethics Committee.

Two hundred forty six children with NS were admitted and 124 patients $(50 \%)$ with 126 episodes had infection. Of these patients, $85(68.5 \%)$ were boys and 39 (31.45\%) were girls. The mean age of onset of NS was 3.42 $( \pm 2.31) \mathrm{y}$; mean age at which they presented to our center was $4.1( \pm 2.53)$ y and mean age they presented with infection was $5.35( \pm 3.48)$ y. Almost $25 \%(n=31)$ were having their first episode of NS. Out of those who had been previously treated, $59 \%(n=73)$ were steroid sensitive and $16.1 \%(n=20)$ were steroid resistant. $13.7 \%(n=17)$ had prior infective complications, out of which 15 had spontaneous bacterial peritonitis (SBP).

Karalanglin Tiewsoh

ktiewsoh@rediffmail.com

1 Division of Pediatric Nephrology, Advanced Pediatrics Center, Post Graduate Institute of Medical Education and Research, Chandigarh 160012, India

2 Department of Microbiology, Post Graduate Institute of Medical Education and Research, Chandigarh, India
One hundred ten patients (88.7\%) with 112 episodes had SBP. However, only 12 (10\%) episodes had classical symptom combination of fever, abdominal pain, vomiting and loose stools. In those having peritonitis, Gram negative bacilli was detected in $14 \%(n=14)$ and Gram positive cocci in $8.1 \%(n=9)$, with a detection rate of $24 \%$ in ascitic fluid. We could isolate organisms in $9.8 \%(n=11), 8$ of which were Gram positive and 3 were Gram negative organisms. Besides usual organisms, Leclercia adecarboxylata, a Gram negative bacilli was grown and it was sensitive to cephalosporins. A small proportion had cellulitis $(n=6)$, pneumonia $(n=5)$, urinary tract infection (UTI: $n=2)$, tuberculosis (TB: $\mathrm{n}=2)$, varicella $(\mathrm{n}=2)$, meningitis $(n=1)$ and septicemia $(\mathrm{n}=1)$. A significant $(n=4 ; 3.3 \%)$ had multiple infections, which was considered as a single infection episode.

Thus, in our setting, infection is the most common cause of hospitalization in NS children, almost all being peritonitis. Though Gram positive bacteria predominates, yet the rise of Gram negative organisms cannot be undermined.

\section{Compliance with Ethical Standards}

Conflict of Interest None.

\section{References}

1. Gipson DS, Messer KL, Tran CL, et al. Inpatient health care utilization in the United States among children, adolescents, and young adults with nephrotic syndrome. Am J Kidney Dis. 2013;61:910-7.

2. Gulati S, Kher V, Gupta A, Arora P, Rai PK, Sharman RK. Spectrum of infections in nephrotic syndrome. Pediatr Nephrol. 1995;9:431-4.

3. Gorensek MJ, Lebel MH, Nelson JD. Peritonitis in children with nephritic syndrome. Pediatrics. 1988;81:849-56.

4. KDIGO clinical practice guideline for glomerulonephritis. Kidney Int Suppl. 2012;2:139-274.

Publisher's Note Springer Nature remains neutral with regard to jurisdictional claims in published maps and institutional affiliations. 